\title{
ENGINEERING A NEW MATERIAL FOR HOT GAS CLEANUP
}

\author{
Annual Technical Progress Report
}

July 1, 2000 -June 30, 2001

T. D. Wheelock, L. K. Doraiswamy, and K. Constant Principal Investigators

T. T. Akiti, Jr. and D. J. L. Hasler Graduate Assistants

Issued: June 2001

DOE Award No. DE-FG26-99FT40587

Chemical Engineering Department, Materials Science and Engineering Department, and Center for Sustainable Environmental Technologies 2114 Sweeney Hall Iowa State University Ames, IA 50011-2230 


\section{$\underline{\text { DISCLAIMER }}$}

This report was prepared as an account of work sponsored by an agency of the United States Government. Neither the United States Government nor any agency thereof, nor any of their employees, makes any warranty, express or implied, or assumes any legal liability or responsibility for the accuracy, completeness, or usefulness of any information, apparatus,

product, or process disclosed, or represents that its use would not infringe privately owned rights. Reference herein to any specific commercial product, process, or service by trade name, trademark, manufacturer, or otherwise does not necessarily constitute or imply its endorsement, recommendation, or favoring by the United States Government or any agency thereof. The views and opinions of the authors expressed herein do not necessarily state or reflect those of the United States Government or any agency thereof. 


\section{ENGINEERING A NEW MATERIAL FOR HOT GAS CLEANUP}

Annual Technical Progress Report

July 1, 2000 -June 30, 2001

T. D. Wheelock, L. K. Doraiswamy, and K. Constant Principal Investigators

\section{$\underline{\text { ABSTRACT }}$}

The overall objective of this project is the engineering development of a reusable calciumbased sorbent for desulfurizing hot coal gas. A two-step pelletization method has been employed to produce relatively strong, "core-in-shell," spherical pellets. Each pellet consists of a highly reactive core surrounded by a strong, inert, porous shell. A suitable core is composed largely of $\mathrm{CaO}$ which reacts with $\mathrm{H}_{2} \mathrm{~S}$ to form $\mathrm{CaS}$. Pellet cores have been prepared by pelletizing either pulverized limestone or plaster of Paris, and shells have been made of various materials. The most suitable shell material has been formed from a mixture of alumina and limestone particles. The core-in-shell pellets require treatment at high temperature to convert the core material to $\mathrm{CaO}$ and to partially sinter the shell material.

Pellet cores derived from plaster of Paris have proved superior to those derived from limestone because they react more rapidly with $\mathrm{H}_{2} \mathrm{~S}$ and their reactivity does not seem to decline with repeated loading and regeneration. The rate of reaction of $\mathrm{H}_{2} \mathrm{~S}$ with $\mathrm{CaO}$ derived from either material is directly proportional to $\mathrm{H}_{2} \mathrm{~S}$ concentration. The rate of reaction does not appear to be affected significantly by temperature in the range of $1113 \mathrm{~K}\left(840^{\circ} \mathrm{C}\right)$ to $1193 \mathrm{~K}\left(920^{\circ} \mathrm{C}\right)$ but decreases markedly at $1233 \mathrm{~K}\left(960^{\circ} \mathrm{C}\right)$. The rate is not affected by shell thickness within the range tested, which also provides adequate compressive strength. 


\section{TABLE OF CONTENTS}

\begin{tabular}{lr}
\multicolumn{1}{c}{} & Page \\
\hline IISCLAIMER & ii \\
\hline ABSTRACT & iii \\
\hline LIST OF GRAPHICAL MATERIAL & $\mathrm{v}$ \\
\hline INTRODUCTION & 1 \\
\hline EXECUTIVE SUMMARY & 3 \\
\hline EXPERIMENTAL & 4 \\
\hline Materials & 4 \\
\hline Methods & 4 \\
\hline RESULTS AND DISCUSSION & 6 \\
\hline Pellet Properties & 6 \\
\hline Sorbent Characteristics & 8 \\
\hline Sorbent Loading and Regeneration & 17 \\
\hline CONCLUSIONS & 22 \\
\hline REFERENCES & 24 \\
\hline \hline APPENDIX & 24 \\
\hline Publications & 24 \\
\hline Presentations & 24 \\
\hline
\end{tabular}




\section{LIST OF GRAPHICAL MATERIAL}

Page

Figure 1. Effect of shell thickness on the absorption capacity of limestone-based, corein-shell pellets. Absorption was conducted with 1.1 vol. $\% \mathrm{H}_{2} \mathrm{~S}$ at $1153 \mathrm{~K}$ $\left(880^{\circ} \mathrm{C}\right)$.

Figure 2. Effect of shell thickness on absorption capacity of hemihydrate-based, corein-shell pellets. Absorption was conducted with 1.1 vol. $\% \mathrm{H}_{2} \mathrm{~S}$ at $1153 \mathrm{~K}$ $\left(880^{\circ} \mathrm{C}\right)$.

Figure 3. Effect of $\mathrm{H}_{2} \mathrm{~S}$ concentration on absorption rate of limestone-based, core-inshell pellets. Runs were conducted at $1153 \mathrm{~K}\left(880^{\circ} \mathrm{C}\right)$.

Figure 4. Effect of $\mathrm{H}_{2} \mathrm{~S}$ concentration on absorption rate of hemihydrate-based, corein-shell pellets. Runs were conducted at $1153 \mathrm{~K}\left(880^{\circ} \mathrm{C}\right)$.

Figure 5. Effect of $\mathrm{H}_{2} \mathrm{~S}$ concentration on initial conversion rate for different types of core-in-shell pellets at $1153 \mathrm{~K}\left(880^{\circ} \mathrm{C}\right)$.

Figure 6. Effect of temperature on absorption rate of limestone-based, core-in-shell pellets. Runs were conducted with 1.1 vol. $\% \mathrm{H}_{2} \mathrm{~S}$ in nitrogen.

Figure 7. Effect of temperature on absorption rate of hemihydrate-based, core-in-shell pellets. Runs were conducted with 1.1 vol. $\% \mathrm{H}_{2} \mathrm{~S}$ in nitrogen.

Figure 8. Results achieved when a limestone-based core was subjected to a multicycle absorption/regeneration test. Absorption was conducted with 3.0 vol. $\% \mathrm{H}_{2} \mathrm{~S}$ at $1193 \mathrm{~K}\left(920^{\circ} \mathrm{C}\right)$. Regeneration was conducted at $1323 \mathrm{~K}\left(1050^{\circ} \mathrm{C}\right)$.

Figure 9. Comparison of the absorption rates achieved during the $1^{\text {st }}$ and the $7^{\text {th }}$ cycles for a pellet core made from reagent grade calcium carbonate. Absorption was conducted with 3.0 vol. $\% \mathrm{H}_{2} \mathrm{~S}$ at $1193 \mathrm{~K}\left(920^{\circ} \mathrm{C}\right)$ and regeneration was conducted at $1323 \mathrm{~K}\left(1050^{\circ} \mathrm{C}\right)$.

Figure 10. Results achieved when a plaster-based, $3.35 \mathrm{~mm}$ diameter core was subjected to a multicycle absorption/regeneration test. Absorption was conducted with 3.0 vol. $\% \mathrm{H}_{2} \mathrm{~S}$ at $1193 \mathrm{~K}\left(920^{\circ} \mathrm{C}\right)$ and regeneration was conducted at $1323 \mathrm{~K}$ $\left(1050^{\circ} \mathrm{C}\right)$.

Figure 11. Results achieved when a plaster-based, core-in-shell pellet was subjected to a multicycle absorption/regeneration test. Absorption was conducted with 3.0 vol. $\% \mathrm{H}_{2} \mathrm{~S}$ at $1193 \mathrm{~K}\left(920^{\circ} \mathrm{C}\right)$ and regeneration was conducted at $1323 \mathrm{~K}$ $\left(1050^{\circ} \mathrm{C}\right)$. 


\section{$\underline{\text { INTRODUCTION }}$}

The overall purpose of this project is the engineering development of a superior, reusable calcium-based sorbent for desulfurizing hot coal gas. The groundwork for this project was laid in a previous investigation which showed that a promising sorbent could be prepared by pelletizing a mixture of pulverized limestone and calcium aluminate cement in two stages so as to produce a layered structure (1). The basic concept evolved into a core-in-shell pellet structure in which a relatively weak but highly reactive core is encased in a stronger but less reactive shell.

The present project was undertaken to improve upon earlier results by considering other types of core and shell materials and by optimizing preparation conditions. During the first year of the project it was shown that a more suitable shell material can be made by combining alumina particles of different sizes with limestone particles and then calcining the mixture at high temperature to cause partial sintering of the material (2). The composition which produced the strongest shell material was determined and applied as a coating to pellet cores made of limestone. It was found advantageous to incorporate $10 \mathrm{wt} . \%$ ultrafine-size particles of alumina in the cores to improve their green strength and handleability. Several batches of core-in-shell pellets were produced with limestone cores and the optimum shell composition. The absorption capacity, crushing strength, and other important characteristics of the pellets were determined.

The results achieved during the second year of the project are described below in detail. Numerous batches of core-in-shell pellets were prepared with the optimum shell composition and with cores made of either limestone or plaster of Paris. Upon calcination the cores were converted to calcium oxide, and the shells were converted to a strong, inert porous material. The absorption characteristics, crushing strength, and other important properties are reported for the 
different sorbent formulations. In addition, a few pellets were subjected to multicycle loading and regeneration tests to evaluate sorbent performance and durability. 


\section{EXECUTIVE SUMMARY}

This project is directed towards the engineering development of a superior and reusable calcium-based sorbent for desulfurizing hot coal gas. It had been shown previously that a promising sorbent could be prepared by a two-step pelletization method which produced spherical pellets with a limestone core encased in a strong porous shell (1). It had also been shown that suitable shells could be made by coating the limestone cores with a mixture of limestone and alumina particles and then calcining the resulting pellets to cause particle sintering of the mixture (2).

At present the investigation is focused on improving the physical properties and long-term chemical reactivity of the sorbent since an important objective is the development of a sorbent which can be loaded and regenerated repeatedly. During loading the cores which have been converted to $\mathrm{CaO}$ react with $\mathrm{H}_{2} \mathrm{~S}$ to form $\mathrm{CaS}$. During regeneration the $\mathrm{CaS}$ is converted back to $\mathrm{CaO}$ by repeated oxidation and reduction.

Numerous batches of core-in-shell pellets have been prepared and tested to investigate the effectiveness of different potential core materials and preparation conditions. Some batches have been made with limestone cores, whereas other batches have been made with plaster of Paris cores. In most cases the limestone cores have also contained $10 \mathrm{wt} \% \%$ alumina to improve the green strength of the cores. The cores have been coated with a mixture of alumina and limestone particles which provides a strong but porous shell after calcinations at $1373 \mathrm{~K}\left(1100^{\circ} \mathrm{C}\right)$ for $2 \mathrm{hr}$. Shell thickness has been varied among batches to determine its effect on pellet strength and chemical reactivity. The results have shown that the compressive strength is directly proportional to shell thickness and that the rate of reaction of the pellets with $\mathrm{H}_{2} \mathrm{~S}$ is not affected significantly over a limited range of shell thickness.

The results have also shown that the rate of reaction is directly proportional to $\mathrm{H}_{2} \mathrm{~S}$ concentration and virtually independent of temperature in the range of $1113 \mathrm{~K}\left(840^{\circ} \mathrm{C}\right)$ to $1193 \mathrm{~K}\left(920^{\circ} \mathrm{C}\right)$. However, the rate decreases appreciably at $1233 \mathrm{~K}\left(960^{\circ} \mathrm{C}\right)$. Furthermore, the results have shown that core-in-shell pellets made with plaster cores react more rapidly than those made with limestone cores. On the other hand, the ultimate absorption capacity of the limestone-based pellets is higher.

By subjecting core-in-shell pellets to repeated loading and regeneration it was shown that the chemical reactivity of limestone-based pellets declines appreciably from cycle to cycle while the reactivity of plaster-based pellets does not. This difference seems due to a difference in the sintering characteristics of the two materials. 


\section{EXPERIMENTAL}

$\underline{\text { Materials }}$

Several materials were used for the preparation of different sorbent formulations. One of the principal materials was limestone which was obtained either from the Ames, Iowa, quarry of Martin Marietta Aggregates or from the Three Rivers Quarry located near Smithland, Kentucky. According to the suppliers, the Iowa limestone contained over $99 \% \mathrm{CaCO}_{3}$, whereas the Kentucky limestone typically contained $92.8 \% \mathrm{CaCO}_{3}, 5.9 \% \mathrm{MgCO}_{3}$, and $1.1 \% \mathrm{SiO}_{2}$ after drying. The particle size of these materials used for pelletization ranged from 44 to $297 \mu \mathrm{m}$. Other materials used in sorbent formulations included reagent grade calcium carbonate and commercial grade plaster of Paris. Both materials consisted of particles smaller than $37 \mu \mathrm{m}$. A combination of X-ray diffraction and X-ray fluorescence analysis showed the plaster of Paris to have the following composition by weight: $77 \%$ calcium sulfate hemihydrate, $15 \%$ calcite, $6 \%$ dolomite, and $2 \%$ other minerals. Sorbent pellet shells were made largely of a mixture of A-16 SG alumina powder and T-64 tabular alumina particles both supplied by Alcoa. The first material had a median particle diameter of $0.88 \mu \mathrm{m}$ and the second a median particle diameter of $8.65 \mu \mathrm{m}$.

\section{Methods}

The core-in-shell pellets were prepared in two stages using a small bench-scale drum pelletizer which had a diameter of $25 \mathrm{~cm}$ and could be operated at various speeds. The pellet cores were prepared first by placing a measured amount of the appropriate powdered material in the drum, and as the drum revolved at a constant $60 \mathrm{rpm}$, the powder was sprayed at frequent intervals with water or a dilute lignin solution until pellets formed. Water was used for 
pelletizing plaster of Paris, whereas a lignin solution was used for pelletizing limestone or a mixture of limestone and A-16 SG alumina. The pellets were grown into larger pellets by adding more material. When the pellets reached a desired size, they were allowed to tumble for $1.0 \mathrm{hr}$. to improve their sphericity and uniformity. The pellets were then separated into various sizes by hand screening with 5, 6, and 7 mesh screens. Pellets of a particular mesh size were reloaded into the pelletizer for coating with the optimum shell formulation which consisted of $48 \%$ T-64 tabular alumina, 32\% A-16 SG alumina, and 20\% limestone $(-297 /+44 \mu \mathrm{m})$. While the drum speed was kept constant, a measured amount of the coating material was added gradually as the pellets were sprayed with a dilute lignin solution. Once coated, the pellets were allowed to tumble for $2.0 \mathrm{hr}$. to consolidate the coating. During this time the pellets were sprayed at $5 \mathrm{~min}$. intervals with a dilute lignin solution. The coated pellets were subsequently removed and screened. Pellets of the desired size were then calcined at $1373 \mathrm{~K}\left(1100^{\circ} \mathrm{C}\right)$ for $2.0 \mathrm{hr}$.

The compressive strength of the spherical pellets was determined by measuring the force required to break a pellet when a single sample was placed between the two plates of an Accuforce EZ250 test stand, and the upper plate was lowered at a rate of $10 \mathrm{~mm} / \mathrm{min}$. The absorption characteristics of the pellets were determined by measuring the gain in weight of a single pellet as it was treated with the gas mixture containing $\mathrm{H}_{2} \mathrm{~S}$ and $\mathrm{N}_{2}$ inside of a vertical tubular reactor made of $25 \mathrm{~mm}$ diameter quartz tubing. The gas mixture of known composition was supplied to the reactor at a flow rate of $500 \mathrm{~cm}^{3} / \mathrm{min}$. measured at room temperature and pressure. The system temperature was determined with a thermocouple protected by a quartz thermowell located just below the suspended basket. The temperature was maintained by an electric furnace which surrounded the reactor. 
To regenerate a sorbent after it had been largely converted to $\mathrm{CaS}$, the pellet was left in the reaction system, and as nitrogen was passed through the system, the temperature was normally raised to $1323 \mathrm{~K}\left(1050^{\circ} \mathrm{C}\right)$. Oxygen was then added to the flowing nitrogen to provide a mixture with $20 \mathrm{~mole} \% \mathrm{O}_{2}$ and having a total flow rate of $500 \mathrm{~cm}^{3} / \mathrm{min}$. at room temperature and pressure. After 1 to 5 min. of oxidation, the composition of the gas mixture was changed to 30 mole $\% \mathrm{CO}$ in nitrogen. Then after 1 to $3 \mathrm{~min}$. of reduction, the cycle was repeated. The process was continued until the pellet approached a constant weight.

A similar procedure was used for converting the core of a pellet made with plaster of Paris to $\mathrm{CaO}$. In this case after a freshly made core-in-shell pellet had been calcined, the core would be largely in the form of $\mathrm{CaSO}_{4}$. Subjecting the pellet to a cycle of reduction and then oxidation and repeating the cycle several times converted the $\mathrm{CaSO}_{4}$ to $\mathrm{CaO}$.

\section{$\underline{\text { RESULTS AND DISCUSSION }}$}

\section{$\underline{\text { Pellet Properties }}$}

Numerous batches of core-in-shell pellets were prepared to investigate the effects of shell thickness and different core formulations on the physical properties of the sorbent pellets. All of the pellets were made with the optimum shell composition, i.e., 48\% T-64 tabular alumina, 32\% A-16 SG alumina powder, and 20\% Iowa limestone. The cores were made either of limestone or of plaster of Paris. Most of the limestone cores were made of Iowa limestone and most contained 10\% A-16 SG alumina. After the pellets had been calcined, various physical properties were determined including compressive strength, bulk density, and apparent density. Typical results are presented in Table 1 for several different sorbent formulations. The examples represent pellets made with different core materials and made with shells of different thickness. 


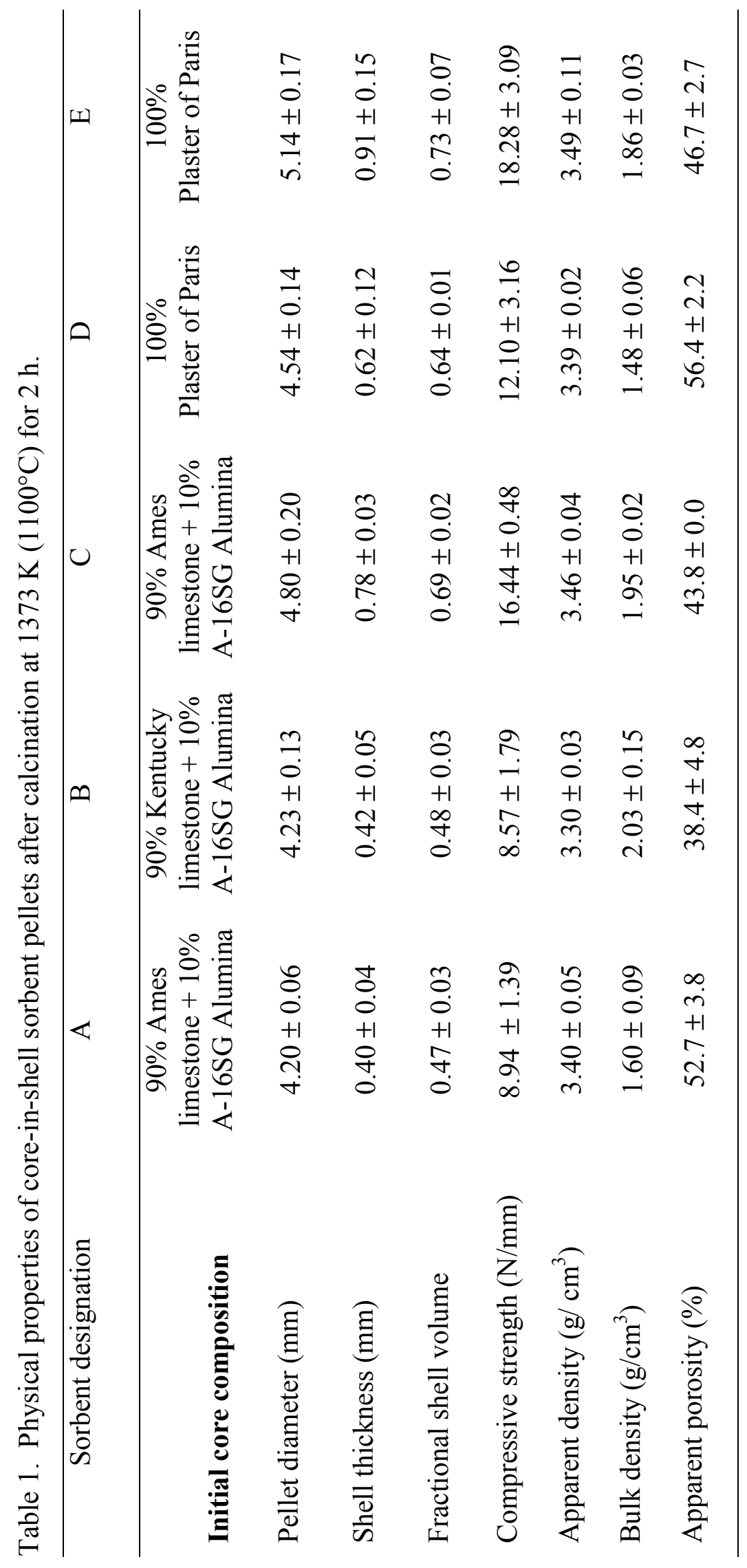


The pellet core diameter was kept within the range of 3.2 to $3.4 \mathrm{~mm}$. The property values listed for each sorbent represent the mean of three batches of pellets. Since the crushing strength was measured on five different pellets selected at random from each batch, each value of compressive strength is based on the breakage of 15 different pellets. The crushing strength correlated extremely well with shell thickness. The following relationship between compressive strength $\mathrm{S}$ and shell thickness $t$ was developed by applying linear regression to the experimental data:

$$
\mathrm{S}=19.5 \mathrm{t}+0.65
$$

Since the correlation coefficient $r$ had a value of 0.993 , this equation seemed to account for most of the variation in the compressive strength and core composition had little effect. According to equation 1 , a shell thickness of $0.43 \mathrm{~mm}$ would withstand a crushing force approaching $9 \mathrm{~N} / \mathrm{mm}$ which is considered adequate for fixed bed applications.

The data in Table 1 indicates only a small variation in the apparent density of pellets made with different formulations and a much larger variation in the bulk density. The bulk density as well as the apparent porosity reflect the fractional pellet volume occupied by open pores. Therefore, formulation D had the largest volume of accessible pores and formulation B the lowest. Since the apparent porosity decreased as the shell thickness increased and made up a larger share of the total pellet volume for a given core material, the porosity of the shells must have been smaller than the porosity of the cores.

\section{$\underline{\text { Sorbent Characteristics }}$}

A series of preliminary absorption tests with several uncoated pellet cores produced highly reproducible results and showed that limestone-based cores and plaster-based cores absorbed equally well when treated at $1153 \mathrm{~K}\left(880^{\circ} \mathrm{C}\right)$ with a gas mixture containing $1.1 \mathrm{vol} . \% \mathrm{H}_{2} \mathrm{~S}$. The 
rate of gain in weight was virtually the same for both materials, and the maximum weight gained was approximately $24 \%$ for both. Although neither material had been precalcined at $1373 \mathrm{~K}$ $\left(1100^{\circ} \mathrm{C}\right)$, the plaster-based cores had been pretreated at $1323 \mathrm{~K}\left(1050^{\circ} \mathrm{C}\right)$ to convert $\mathrm{CaSO}_{4}$ to $\mathrm{CaO}$ by the cyclic process. The limestone-based cores did not require pretreatment since $\mathrm{CaCO}_{3}$ was converted to $\mathrm{CaO}$ when the cores were heated to $1153 \mathrm{~K}\left(880^{\circ} \mathrm{C}\right)$ for the absorption test.

Surprisingly, when calcined core-in-shell pellets were subjected to absorption tests, a difference in the rate of absorption of the two materials was observed. The plaster-based pellets exhibited a higher rate of absorption than the limestone-based pellets under similar treatment conditions. The results suggest that the alumina added to the limestone-based cores may have reacted with part of the $\mathrm{CaO}$ during calcinations at $1373 \mathrm{~K}\left(1100^{\circ} \mathrm{C}\right)$ to form calcium aluminate which affected the absorption characteristics of the pellets.

Several absorption tests were conducted with precalcined core-in-shell pellets to study the effect of increasing shell thickness. Again the tests were conducted at $1153 \mathrm{~K}\left(880^{\circ} \mathrm{C}\right)$ with $1.1 \% \mathrm{H}_{2} \mathrm{~S}$ in a nitrogen mixture. Results obtained with limestone-based pellets are shown in Figure 1 and results with plaster-based pellets in Figure 2. In both cases it is apparent that the ultimate gain in weight due to absorption decreased as shell thickness increased. Also the ultimate gain in weight of limestone-based pellets was greater than that of plaster-based pellets. These effects are the result of expressing the gain in weight as a percentage of the initial pellet mass. As the shell thickness increased, the reactive core mass became a smaller fraction of the total pellet mass since all of the pellets had approximately the same initial core diameter, $3.5 \mathrm{~mm}$. Furthermore, the pellet cores derived from limestone had more $\mathrm{CaO}$ than those derived from plaster because the molar volume of the $\mathrm{CaCO}_{3}$ particles was less than the molar volume of the hydrated $\mathrm{CaSO}_{4}$ particles. 


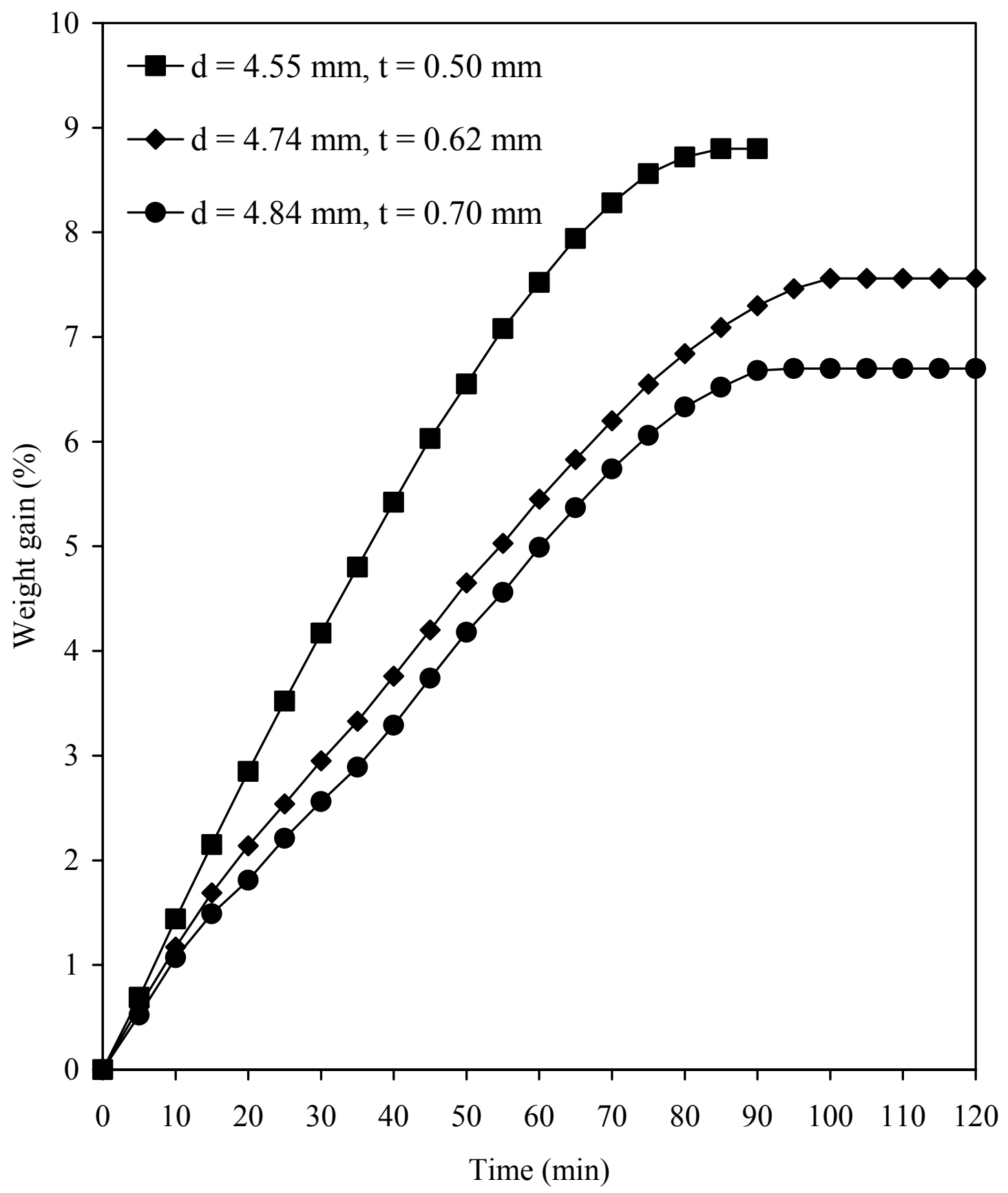

Figure 1. Effect of shell thickness on the absorption capacity of limestone-based, core-in-shell pellets. Absorption was conducted with $1.1 \mathrm{vol} . \% \mathrm{H}_{2} \mathrm{~S}$ at $1153 \mathrm{~K}\left(880^{\circ} \mathrm{C}\right)$. 


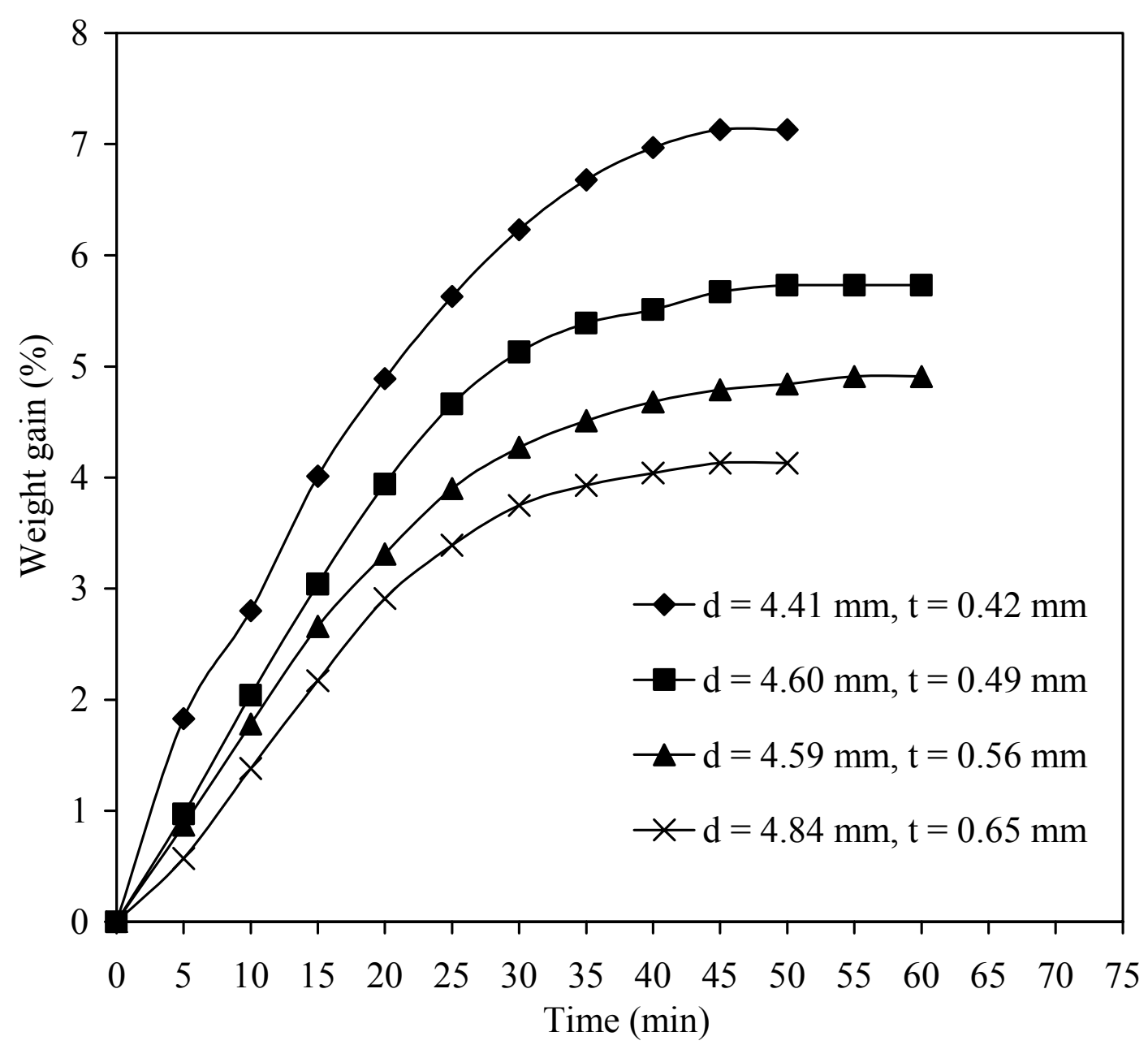

Figure 2. Effect of shell thickness on absorption capacity of hemihydrate-based, core-in-shell pellets. Absorption was conducted with $1.1 \mathrm{vol} . \% \mathrm{H}_{2} \mathrm{~S}$ at $1153 \mathrm{~K}\left(880^{\circ} \mathrm{C}\right)$.

Although Figures 1 and 2 indicate that the rate of weight gain decreased with increasing shell thickness, the actual rate of conversion of $\mathrm{CaO}$ to $\mathrm{CaS}$ did not appear to be affected by shell thickness. This can be seen by comparing the conversion of the different pellets at a particular time. For example, after $30 \mathrm{~min}$. of absorption all of the plaster-based pellets registered a conversion of $68-71 \%$. The small differences among the pellets is not considered significant. Therefore, the rate of absorption did not seem to be limited by the rate of diffusion of gas through the pellet shell. 
Other absorption tests were conducted with precalcined core-in-shell pellets to investigate the effect of $\mathrm{H}_{2} \mathrm{~S}$ concentration on the rate of absorption while holding pellet dimensions and other system parameters constant. The results obtained with limestone-based pellets are presented in Figure 3 and those obtained with plaster-based pellets in Figure 4. Although the average outside diameter of both types of pellets was nearly the same $(4.9-4.8 \mathrm{~mm})$, the average core diameters differed and were 4.0 and $3.5 \mathrm{~mm}$, respectively. Consequently, the average shell thickness was $0.45 \mathrm{~mm}$ for the limestone-based pellets and $0.64 \mathrm{~mm}$ for the plaster-based. In both cases the initial rate of absorption was greatly affected by $\mathrm{H}_{2} \mathrm{~S}$ concentration. In Figure 5 it can be seen that the initial rate of conversion of $\mathrm{CaO}$ to $\mathrm{CaS}$ was directly proportional to $\mathrm{H}_{2} \mathrm{~S}$ concentration. Therefore, the process appeared to be governed initially by first order kinetics. Furthermore, the rate of absorption of $\mathrm{H}_{2} \mathrm{~S}$ was greater for the plaster-based pellets than for the limestone-based pellets even though the limestone-based pellets had thinner shells which indicates that the intrinsic rate of absorption was greater for the plaster-based material than for the limestone-based material.

Additional absorption tests were conducted with precalcined pellets to study the effect of temperature on the rate of absorption of $\mathrm{H}_{2} \mathrm{~S}$. The results are shown in Figures 6 and 7 , respectively, for the two types of pellets. For some of these tests, limestone-based pellets having an average overall diameter of $4.88 \mathrm{~mm}$ and a shell thickness of $0.48-0.55 \mathrm{~mm}$ were employed. Figure 6 indicates very little difference in the rate of absorption over the temperature range from $1113 \mathrm{~K}\left(840^{\circ} \mathrm{C}\right)$ to $1193 \mathrm{~K}\left(920^{\circ} \mathrm{C}\right)$. The small differences in the final weight gain of the different pellets was probably due to differences in sorbent mass. However, the lower rate of absorption observed at $1233 \mathrm{~K}\left(960^{\circ} \mathrm{C}\right)$ was clearly due to the increase in temperature. Similar results were observed with the plaster-based pellets which had an average overall diameter of 


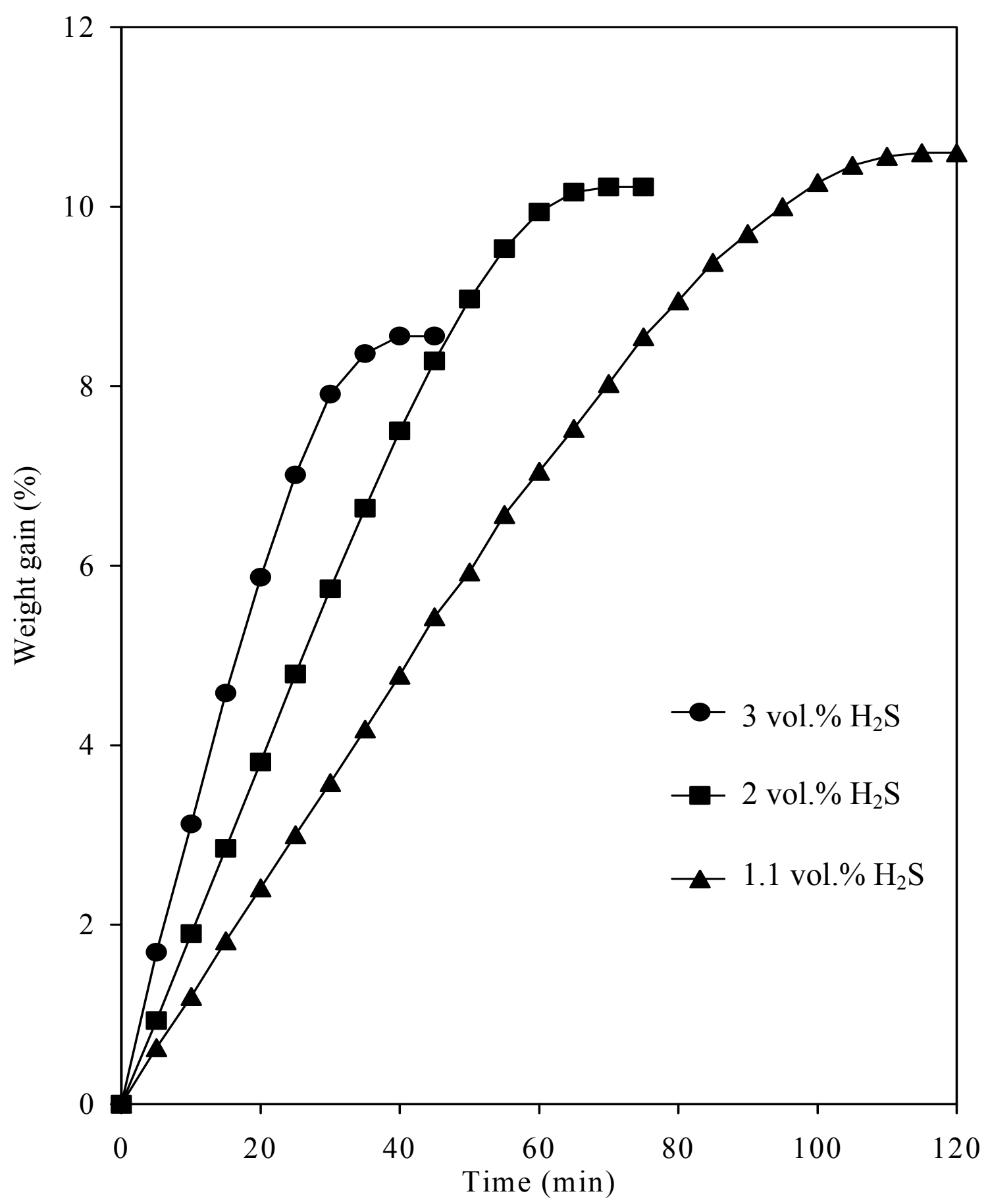

Figure 3. Effect of $\mathrm{H}_{2} \mathrm{~S}$ concentration on absorption rate of limestone-based, core-in-shell pellets. Runs were conducted at $1153 \mathrm{~K}\left(880^{\circ} \mathrm{C}\right)$. 


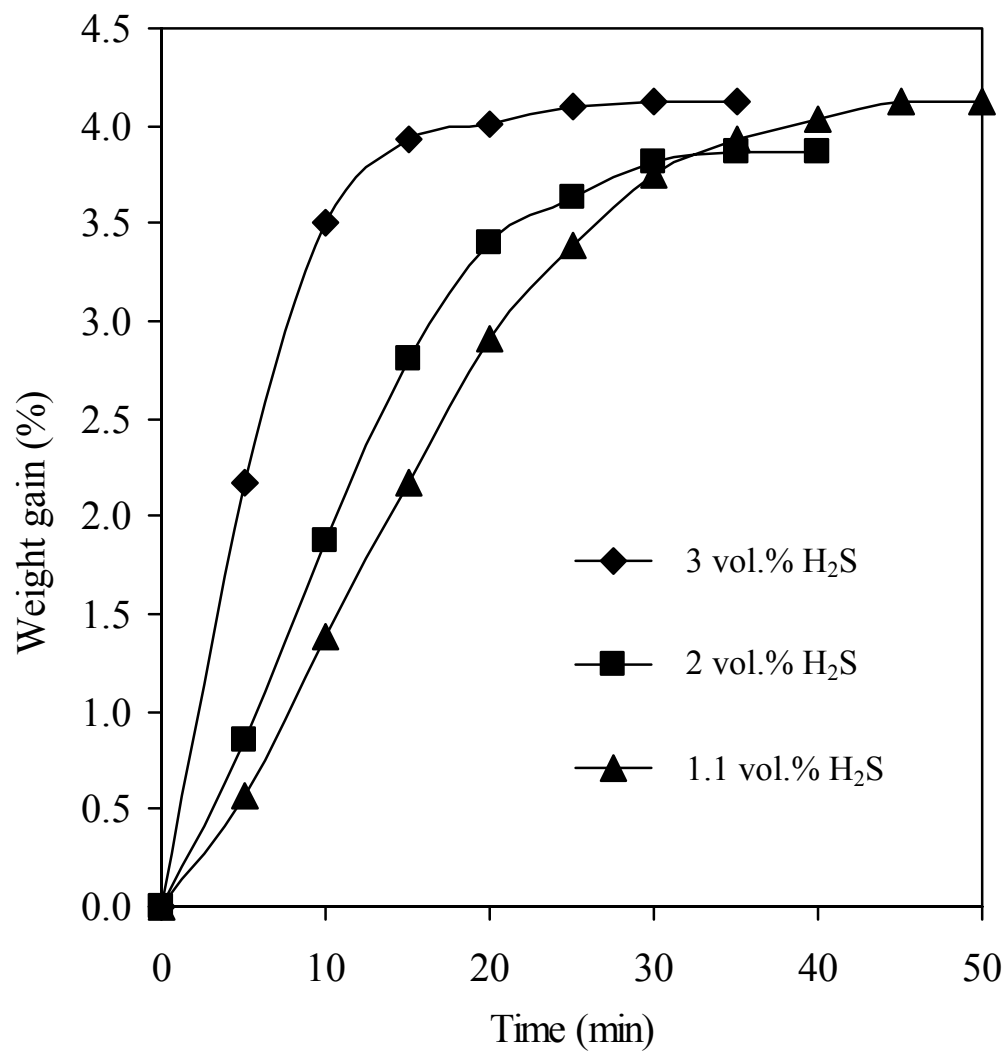

Figure 4. Effect of $\mathrm{H}_{2} \mathrm{~S}$ concentration on absorption rate of hemihydrate-based, core-in-shell pellets. Runs were conducted at $1153 \mathrm{~K}\left(880^{\circ} \mathrm{C}\right)$.

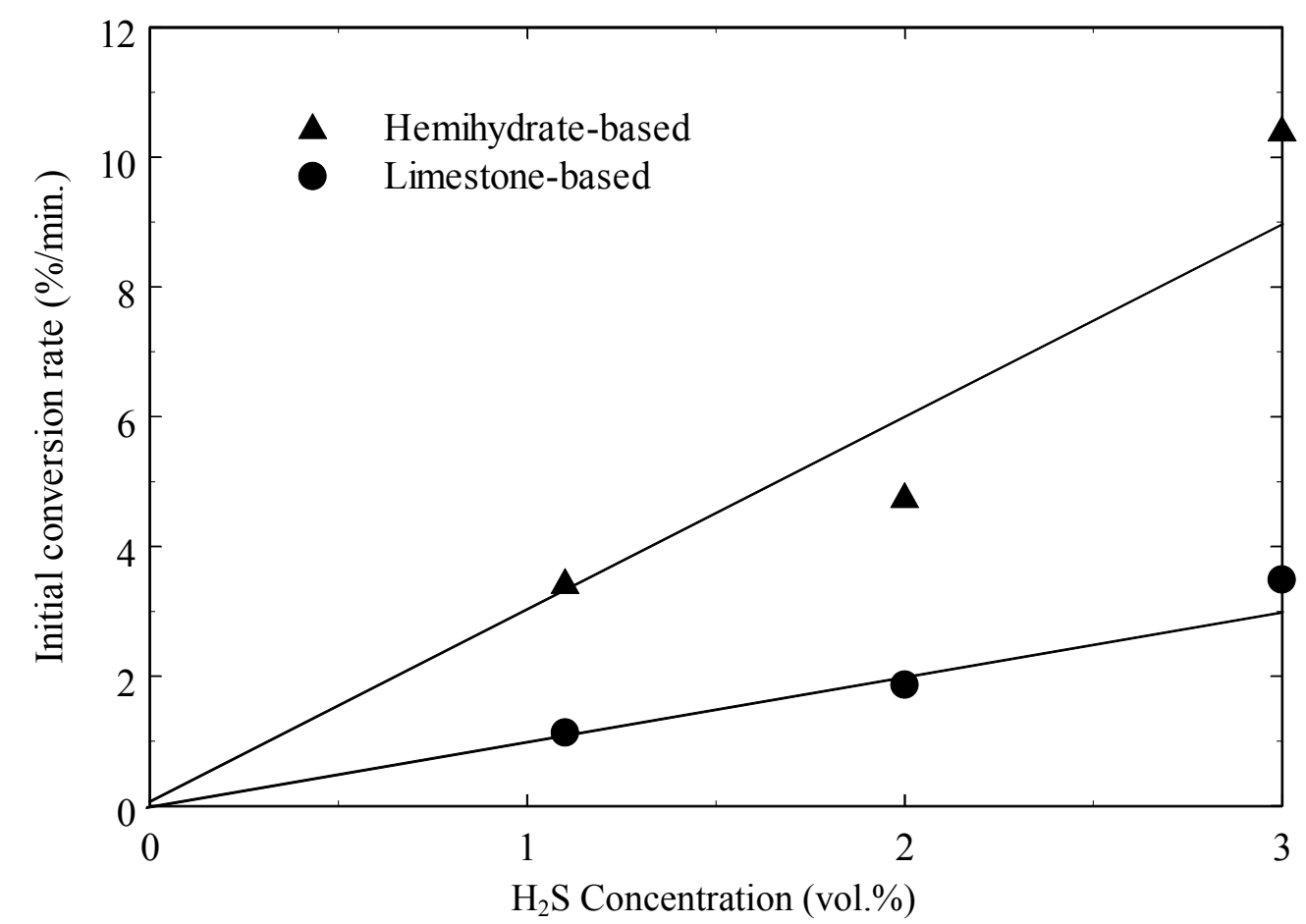

Figure 5. Effect of $\mathrm{H}_{2} \mathrm{~S}$ concentration on initial conversion rate for different types of core-inshell pellets at $1153 \mathrm{~K}\left(880^{\circ} \mathrm{C}\right)$. 


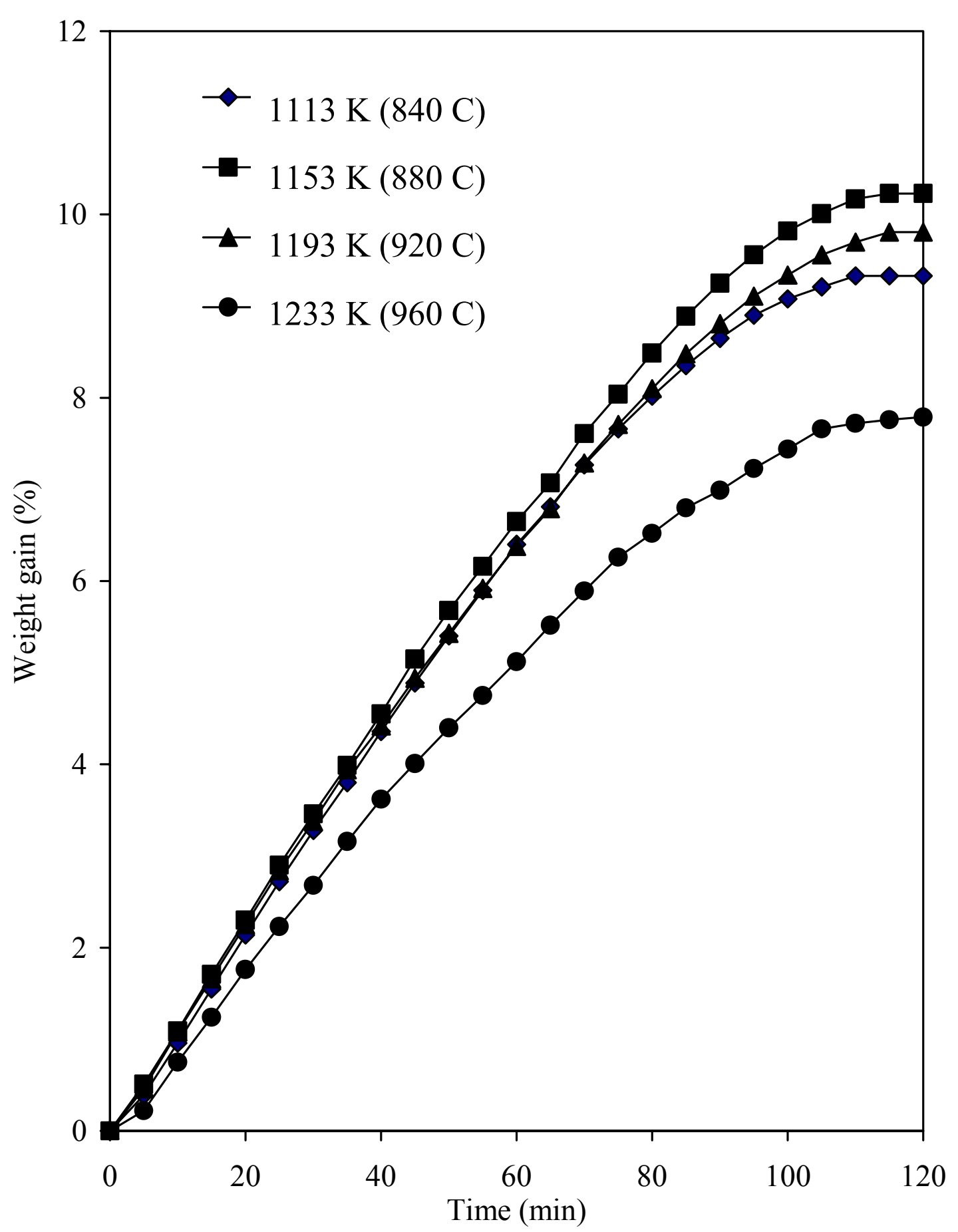

Figure 6. Effect of temperature on absorption rate of limestone-based, core-in-shell pellets. Runs were conducted with 1.1 vol. $\% \mathrm{H}_{2} \mathrm{~S}$ in nitrogen. 


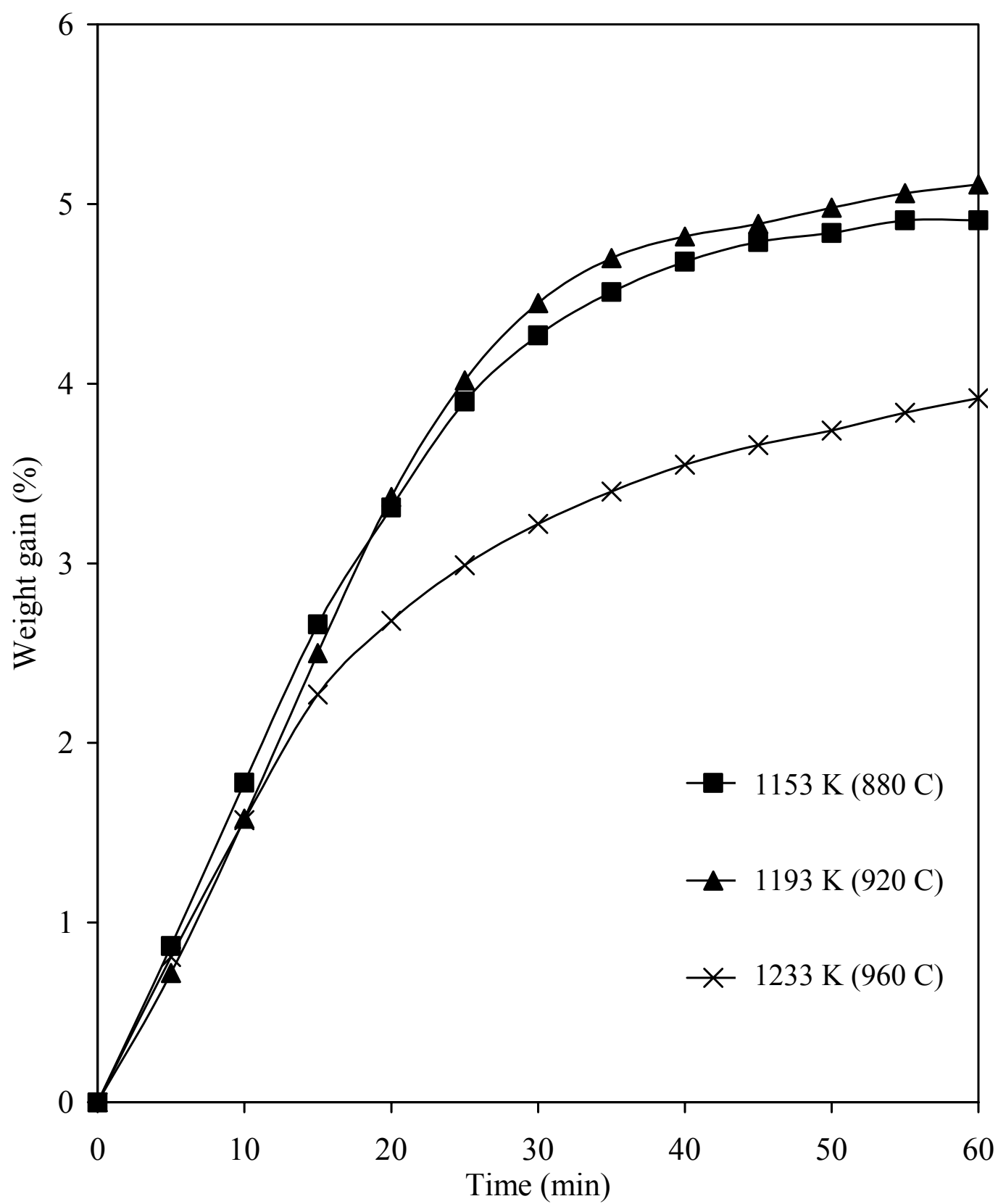

Figure 7. Effect of temperature on absorption rate of hemihydrate-based, core-in-shell pellets. Runs were conducted with 1.1 vol. $\% \mathrm{H}_{2} \mathrm{~S}$ in nitrogen. 
$4.56 \mathrm{~mm}$ and average shell thickness of $0.53 \mathrm{~mm}$ (Figure 7). Again the small difference in rate of absorption observed between $1153 \mathrm{~K}\left(880^{\circ} \mathrm{C}\right)$ and $1193 \mathrm{~K}\left(920^{\circ} \mathrm{C}\right)$ was not significant, whereas the lower absorption rate observed at $1233 \mathrm{~K}\left(960^{\circ} \mathrm{C}\right)$ was significant. Considering that for the two cases the rate of absorption didn't seem to be affected significantly by temperature below $1193 \mathrm{~K}\left(920^{\circ} \mathrm{C}\right)$, the overall rate did not appear limited by chemical reaction. Therefore, the rate controlling mechanism remained elusive. The marked decrease in absorption rate above $1193 \mathrm{~K}\left(920^{\circ} \mathrm{C}\right)$ may have been caused by incipient sintering of the material or a change in the reaction mechanism.

\section{$\underline{\text { Sorbent Loading and Regeneration }}$}

To determine the effects of repeatedly loading and regenerating the different sorbent formulations, several experiments were conducted with uncoated pellet cores and also with corein-shell pellets. During the absorption phase a single pellet was treated at $1153 \mathrm{~K}\left(880^{\circ} \mathrm{C}\right)$ with 3.0 vol. $\% \mathrm{H}_{2} \mathrm{~S}$ in nitrogen for a preset time. Then the flow of $\mathrm{H}_{2} \mathrm{~S}$ was discontinued, and while the flow of nitrogen was continued, the temperature of the system was raised to $1323 \mathrm{~K}\left(1050^{\circ} \mathrm{C}\right)$

for regeneration. Regeneration was conducted by subjecting the pellet to several cycles of oxidation and reduction as previously described. Regeneration was continued until virtually all of the weight gained during the absorption phase had been lost. The temperature of the system was then returned to $1153 \mathrm{~K}\left(880^{\circ} \mathrm{C}\right)$ and the cycle of loading and regeneration repeated.

In one experiment an uncalcined limestone-based pellet core was first converted to $\mathrm{CaO}$ and then subjected to several cycles of loading and regeneration, and the results are shown in Figure 8 . It can be seen that using a constant loading time of $10 \mathrm{~min}$. per cycle resulted in a systematic decrease in the quantity of $\mathrm{H}_{2} \mathrm{~S}$ absorbed. Consequently the gain in pellet weight 


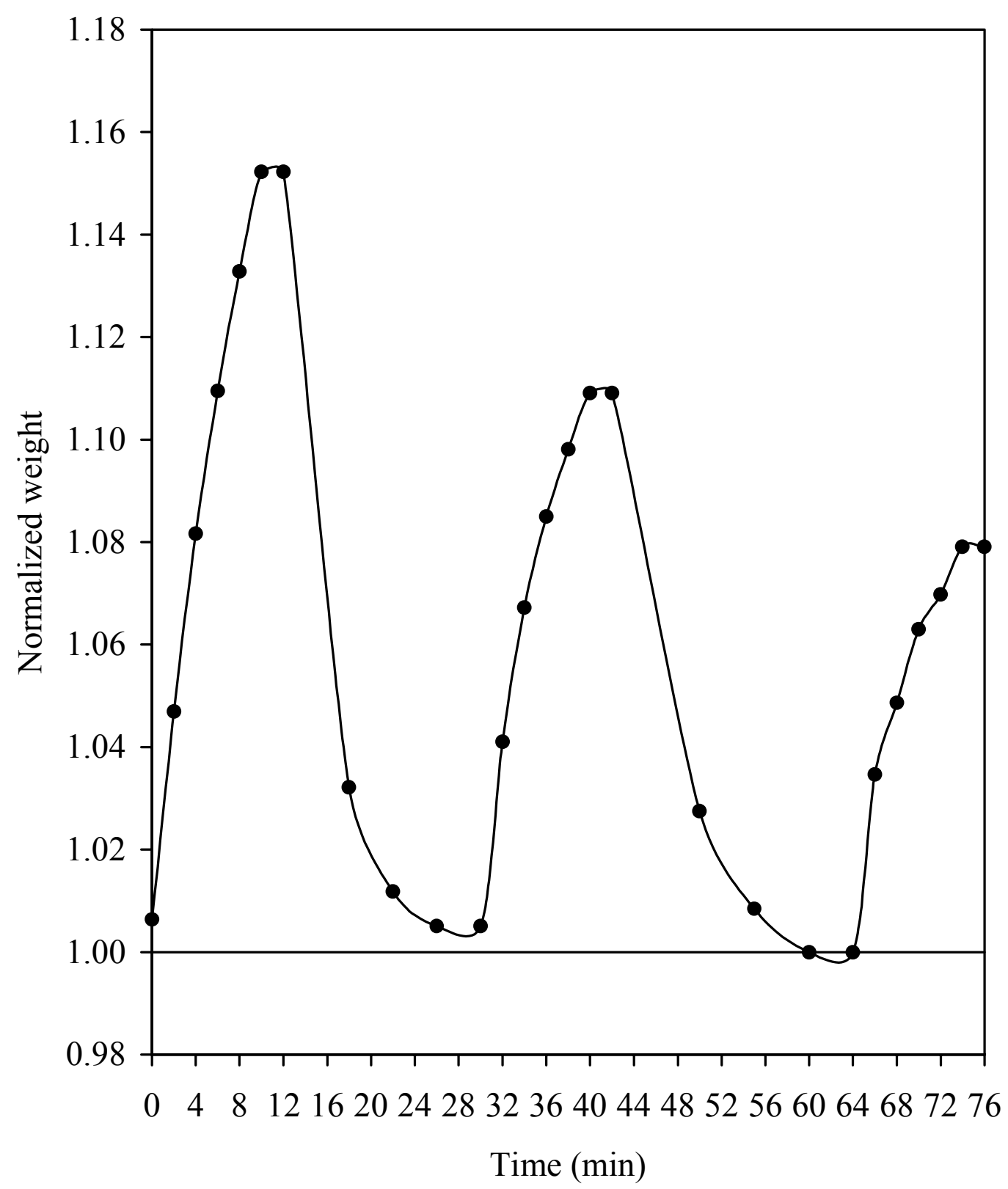

Figure 8. Results achieved when a limestone-based core was subjected to a multicycle absorption/regeneration test. Absorption was conducted with 3.0 vol. $\% \mathrm{H}_{2} \mathrm{~S}$ at $1193 \mathrm{~K}\left(920^{\circ} \mathrm{C}\right)$. Regeneration was conducted at $1323 \mathrm{~K}\left(1050^{\circ} \mathrm{C}\right)$. 
during the third cycle was only half of the weight gained during the first cycle. The results indicate a loss in reactivity of the material which could have been due to sintering.

To see if the presence of limestone impurities or 10\% A-16 SG alumina in the preparation mixture were responsible for the loss in reactivity of the previous pellet core, another experiment was conducted using a pellet core made entirely of reagent grade calcium carbonate. The experiment was conducted as before and a steady decrease in the quantity of $\mathrm{H}_{2} \mathrm{~S}$ absorbed was observed from cycle to cycle. During the seventh cycle the loading time was extended until the pellet had gained as much weight as during the first cycle. Figure 9 shows the gain in weight of the pellet core during the first and last cycles, and it is evident that it required $75 \mathrm{~min}$. for the pellet to gain as much weight during the last cycle as the pellet gained in $10 \mathrm{~min}$. during the first cycle. Therefore, it is clear that even pellets made of pure calcium carbonate experienced a decline in reactivity when subjected to repeated loading and regeneration.

To see whether pellets made from calcium sulfate would behave similarly, an experiment was conducted with a pellet core made from the plaster of Paris. Although the pellet had not been precalcined at $1373 \mathrm{~K}\left(1100^{\circ} \mathrm{C}\right)$, it had been converted to $\mathrm{CaO}$ before subjecting it to several cycles of loading and regeneration. The results presented in Figure 10 show that the sorbent experienced no loss in reactivity over five loading cycles. When a second pellet was subjected to the same treatment, similar results were observed.

In a final experiment, a core-in-shell pellet having a plaster-based core was treated to repeated loading and regeneration as described above. However, the pellet had first been precalcined at $1373 \mathrm{~K}\left(1100^{\circ} \mathrm{C}\right)$ for $2 \mathrm{hr}$. and the core converted to $\mathrm{CaO}$. The pellet had an overall diameter of $4.76 \mathrm{~mm}$ and an inner core diameter of $3.35 \mathrm{~mm}$. The results presented in 


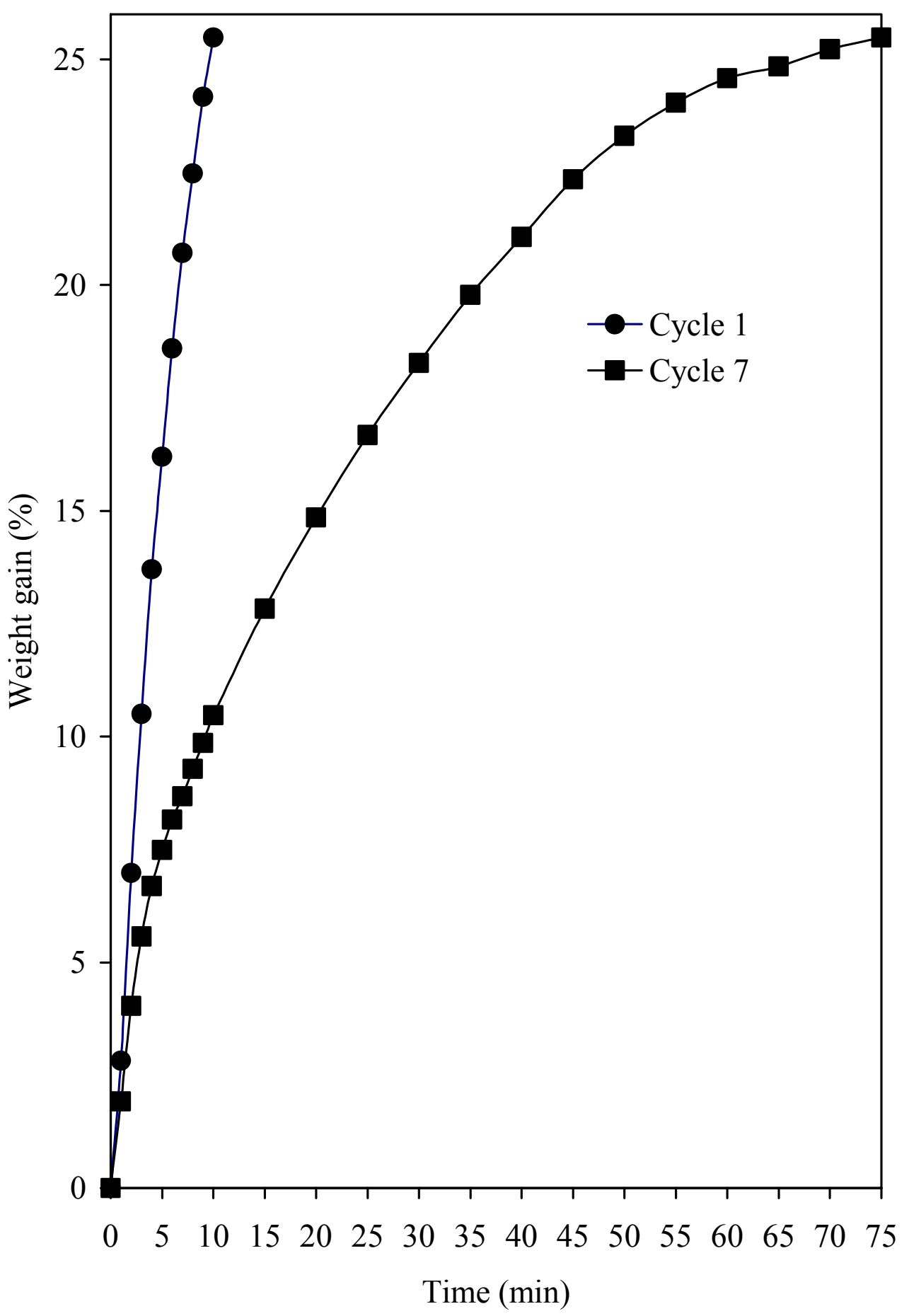

Figure 9. Comparison of the absorption rates achieved during the $1^{\text {st }}$ and the $7^{\text {th }}$ cycles for a pellet core made from reagent grade calcium carbonate. Absorption was conducted with 3.0 vol. $\% \mathrm{H}_{2} \mathrm{~S}$ at $1193 \mathrm{~K}\left(920^{\circ} \mathrm{C}\right)$ and regeneration was conducted at $1323 \mathrm{~K}$ $\left(1050^{\circ} \mathrm{C}\right)$. 


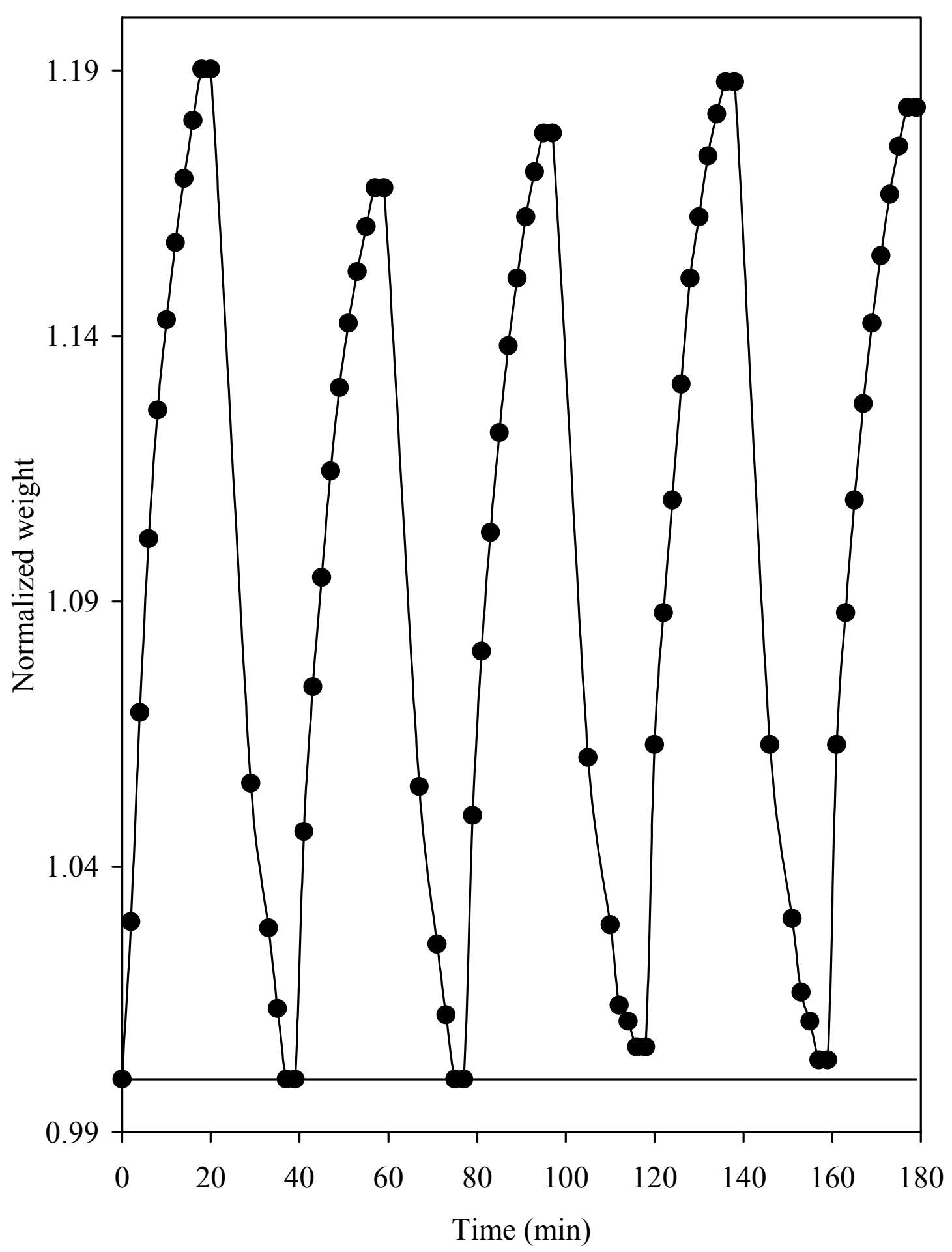

Figure 10. Results achieved when a plaster-based, $3.35 \mathrm{~mm}$ diameter core was subjected to a multicycle absorption/regeneration test. Absorption was conducted with 3.0 vol.\% $\mathrm{H}_{2} \mathrm{~S}$ at $1193 \mathrm{~K}\left(920^{\circ} \mathrm{C}\right)$ and regeneration was conducted at $1323 \mathrm{~K}\left(1050^{\circ} \mathrm{C}\right)$. 
Figure 11 indicate no loss in reactivity over 10 loading cycles. In fact the results show a slight increase in the weight gained from cycle to cycle. Of course, the amount of weight gained in each cycle was low compared to the weight gained by a bare core. The core-in-shell pellet had a relatively thick shell $(0.70 \mathrm{~mm})$ which limited the relative gain in weight due to reaction with $\mathrm{H}_{2} \mathrm{~S}$ and also may have limited the rate of diffusion of $\mathrm{H}_{2} \mathrm{~S}$ into the core.

\section{CONCLUSIONS}

The engineering development of a reusable, calcium-based, core-in-shell sorbent was advanced by investigating the effects of shell thickness and core composition on overall pellet strength and absorption characteristics. The results indicate that the crushing strength of a pellet is directly proportional to shell thickness for a specific core diameter. The results also indicate that the rate of absorption is not affected by shell thickness over the range tested. Therefore, the rate of diffusion of $\mathrm{H}_{2} \mathrm{~S}$ through the shell is not limiting the rate of absorption. The initial rate of absorption is directly proportional to $\mathrm{H}_{2} \mathrm{~S}$ concentration. However, the rate of absorption does not appear to be affected by temperature within the range of $1113 \mathrm{~K}\left(840^{\circ} \mathrm{C}\right)$ to $1193 \mathrm{~K}\left(920^{\circ} \mathrm{C}\right)$, but a lower rate is observed at $1233 \mathrm{~K}\left(960^{\circ} \mathrm{C}\right)$ possibly due to partial sintering of the sorbent material.

Pellet cores derived from plaster of Paris proved superior to those derived from limestone in two important respects. Under similar treatment conditions the plaster-based pellets reacted more rapidly with $\mathrm{H}_{2} \mathrm{~S}$ and their reactivity did not seem to decline with repeated loading and regeneration. On the other hand, the absorption capacity of the limestone-based pellets was greater than that of plaster-based pellets of equal size. 


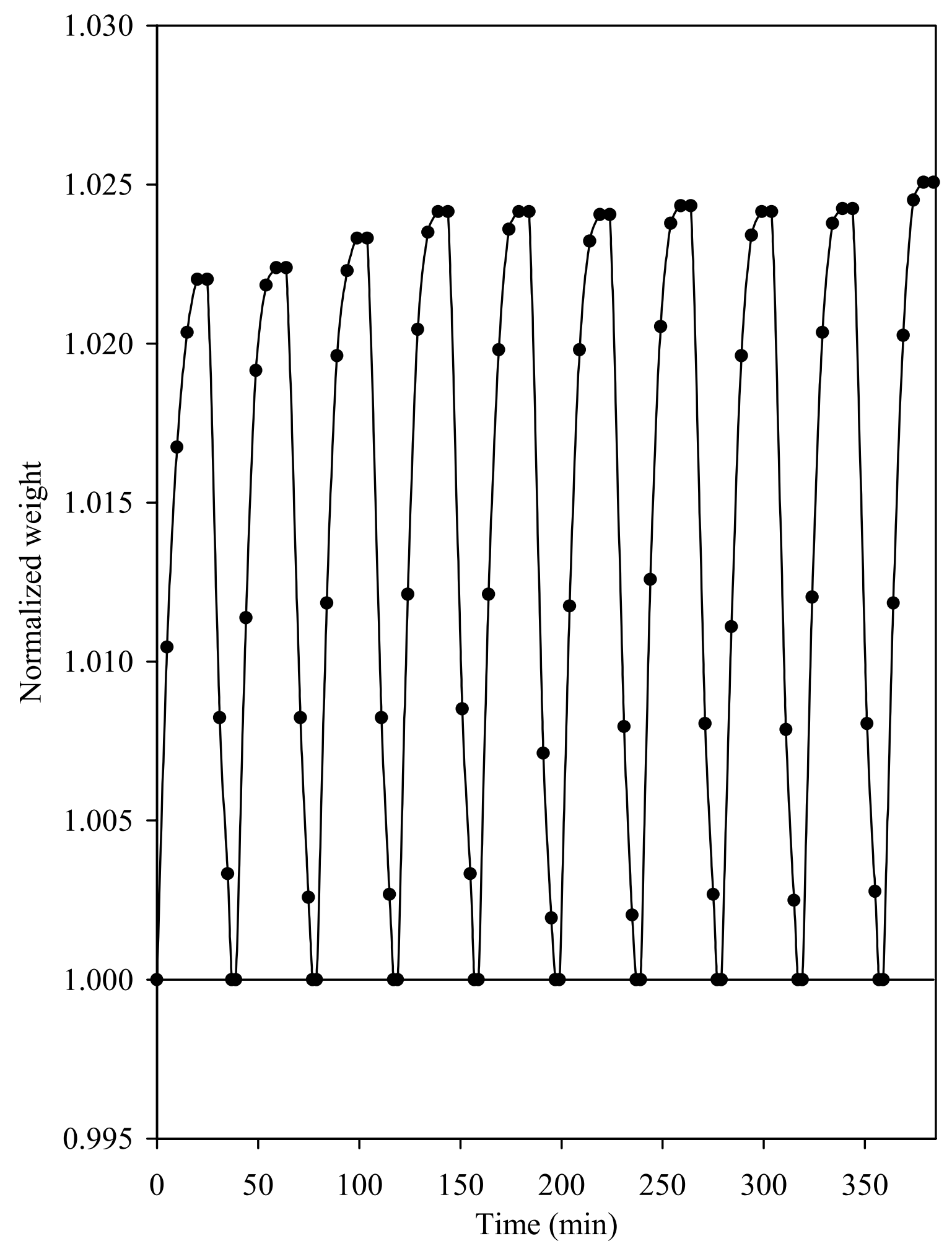

Figure 11. Results achieved when a plaster-based, core-in-shell pellet was subjected to a multicycle absorption/regeneration test. Absorption was conducted with 3.0 vol.\% $\mathrm{H}_{2} \mathrm{~S}$ at $1193 \mathrm{~K}\left(920^{\circ} \mathrm{C}\right)$ and regeneration was conducted at $1323 \mathrm{~K}\left(1050^{\circ} \mathrm{C}\right)$. 
The results of this work point the way for further improvement in the development of a superior sorbent for desulfurizing hot coal gas. The eventual completion of this development will have a highly positive impact on the efficiency of electrical power generation from coal.

\section{$\underline{\text { REFERENCES }}$}

1. T. D. Wheelock, L. K. Doraiswamy, K. Constant, T. T. Akiti, Jr., and J. Zhu, "Development of a Calcium-Based Sorbent for Hot Gas Cleanup," Final Technical Progress Report, October 1, 1996 - September 30, 1999, DOE Grant No. DE-FG22-96PC96203, Chemical Engineering Dept., Materials Science and Engineering Dept., and Center for Sustainable Environmental Technologies, Iowa State University, Ames, Iowa.

2. T. D. Wheelock, L. K. Doraiswamy, K. Constant, T. T. Akiti, Jr., and D. J. L. Hasler, "Engineering a New Material for Hot Gas Cleanup," Annual Technical Progress Report, July 1, 1999 - December 31, 1999, DOE Award No. DE-FG26-99FT40587, Chemical Engineering Dept., Materials Science and Engineering Dept., and Center for Sustainable Environmental Technologies, Iowa State University, Ames, Iowa.

\section{$\underline{\text { APPENDIX }}$}

The results of this research have also been reported in various technical publications and presentations which are listed below.

\section{$\underline{\text { Publications }}$}

Tetteh Akiti, "Development of a regenerable calcium-based sorbent for hot gas cleanup," Ph.D. Thesis, 2001, Iowa State University, Ames, Iowa.

T. T. Akiti, Jr., K. P. Constant, L. K. Doraiswamy, and T. D. Wheelock, “An Improved Core-inShell Sorbent for Desulfurizing Hot Coal Gas," Advances in Environmental Research (in press).

\section{$\underline{\text { Presentations }}$}

D. Hasler (speaker), K. Constant, and T. D. Wheelock, “A calcium-based sorbent for high temperature desulfurization," $113^{\text {th }}$ Annual Meeting, Iowa Academy of Science, Des Moines, Iowa, April 20-21, 2001.

T. D. Wheelock (speaker), L. K. Doraiswamy, and K. Constant, "Engineering a New Material for Hot Gas Cleanup," University Coal Research Contractors Review Conference, Pittsburgh, PA, June 5-6, 2001. 